\title{
São Tomás de Aquino O QUE É a VERDADE?
}

Maria Leonor Xavier ${ }^{1}$

(Universidade de Lisboa)

O texto que aqui se apresenta sob o título de "O que é a verdade?" é uma versão portuguesa do artigo primeiro (a.1) da primeira questão (q.1) da vasta colecção de 253 questões disputadas, Questões Disputadas sobre a Verdade (Quaestiones disputatae de veritate), que $\mathrm{S}$. Tomás de Aquino compôs durante o primeiro período de três anos, 1256-1259, em que ensinou na Universidade de Paris, correspondendo a uma actividade lectiva de notável intensidade, como realçou M.-D. Chenu². A leccionação exigia, então, a preparação escrita e a discussão pública da questão disputada (quaestio disputata): o método argumentativo de pensar e expor as matérias de ensino, que incluía a sistematização das opiniões dos antigos e contemporâneos sobre a matéria em causa e uma tomada de posição racionalmente fundamentada por parte do mestre, filósofo ou teólogo. Neste contexto universitário, a filosofia e a teologia do séc. XIII eram formas de pensamento argumentativo, e S. Tomás de Aquino era um pensador exímio de questões disputadas.

mlx@mail.telepac.pt

2 "Saint Thomas, pendant les trois premières années 1256-1259 qu'il passe à Paris, va se mettre au régime continu de deux disputes régulières par semaine: activité d'une intensité inouïe, dans ce genre où tant la rédaction définitive que l'acte même de la discussion publique requéraient un effort considérable." M.-D. Chenu, Introduction à l'étude de saint Thomas d'Aquin, $3^{\mathrm{a}}$ ed., Montréal/ Paris, Institut d'Études Médiévales Vrin, 1974, p. 241; "Il est acquis cependant que les 253 questions classées sous le titre De veritate couvrent les trois années du premier enseignement à Paris, selon une distribution régulière de 84,84 et 85 par année scolaire, si bien qu'on a pu, sans trop d'arbitraire, les dater à une semaine près." M.-D. Chenu, Op. cit., p. 242.

Philosophica, 55-56, Lisboa, 2020, pp. 9-21. 
A verdade é não só o tema amplo que permite cobrir as mais de duas centenas de questões derivadas e ramificadas que constituem $D e$ veritate, como é o tema propriamente visado na primeira questão da obra: a questão da verdade. Em geral, uma questão disputada enuncia um tema problemático e complexo, que não se esclarece senão através da resolução de múltiplos problemas particulares - são os artigos que compõem a questão - e a questão da verdade não é excepção a esta forma de complexidade. Assim, a questão da verdade, a primeira questão da obra De veritate, revela a sua densa complexidade interna ao deixar decompor-se nos doze artigos seguintes:

1. O que é a verdade?

2. Se a verdade se encontra mais no intelecto do que nas coisas.

3. Se a verdade existe apenas no intelecto que compõe e divide.

4. Se existe apenas uma verdade pela qual todas as coisas são verdadeiras.

5. Se alguma outra verdade, além da primeira verdade, é eterna.

6. Se a verdade criada é imutável.

7. Se a verdade em Deus se diz essencialmente ou pessoalmente.

8. Se toda a verdade é distinta da primeira verdade.

9. Se a verdade existe no sentido.

10. Se alguma coisa é falsa.

11. Se a falsidade existe nos sentidos.

12. Se a falsidade existe no intelecto.

Esta série de perguntas - os artigos que compõem a questão da verdade - mostra que a verdade se define pela sua relação quer com as coisas quer com os sentidos quer com o intelecto. A relação da verdade com as coisas em geral, isto é, a relação entre verdade e realidade é especialmente visada no artigo primeiro (a.1): o que é a verdade? Aqui está em causa a identidade ou diferença entre a verdade e aquilo que é, o ente. Cabe notar, porém, que este mesmo problema passa a ser visado só no artigo terceiro (a.3) - sobre a comparação entre o verdadeiro e o ente, ou se o verdadeiro e o ente se convertem entre si - da mesma questão da verdade, mas no desenvolvimento mais sucinto que obtém na Suma de Teologia (I, q.16) ${ }^{3}$.

3 Questão com a seguinte ordem de artigos: 1. Se a verdade existe na realidade ou apenas no intelecto; 2. Se existe apenas no intelecto que compõe e divide; 3 . Sobre a comparação do verdadeiro com o ente; 4 . Sobre a comparação do verdadeiro com o bom; 5. Se Deus é a verdade; 6 . Se todas as coisas são verdadeiras por uma verdade única ou por múltiplas verdades; 7. Sobre a eternidade da verdade; 8 . Sobre a sua imutabilidade. 
É que aí, a relação fundamentalmente constituinte da verdade é a relação com o intelecto, desde logo, com o intelecto divino, do qual a verdade depende em primeira instância, residindo nele per se, isto é, de modo substancial (q.16, a.1). Aí a teoria da verdade evidencia prioritariamente o seu fundamento teológico, de acordo com o contexto da obra em que se insere, que é uma suma de teologia. Em virtude dessa redução ao intelecto divino, como sujeito fundador, a teoria tomasiana da verdade pode ser considerada uma forma de idealismo gnosiológico.

Todavia, o fundamento teológico da verdade não exclui um outro fundamento: o ontológico. Não existindo ainda na filosofia medieval a palavra "ontologia", a que nos referimos ao admitirmos que a teoria da verdade tem também um fundamento ontológico em S. Tomás de Aquino? Referimo-nos à metafísica, entendida como uma "filosofia transcendental", no sentido em que Jan A. Aertsen assim caracteriza a própria filosofia medieval, na sua obra: Medieval Philosophy as Transcendental Thought. From Philip the Chancellor (ca. 1225) to Francisco Suárez (2012). Esta obra do séc.XXI faz a história da filosofia medieval, segundo a doutrina dos transcendentais, valorizando de modo certeiro, a nosso ver, esta doutrina, como um contributo original da filosofia medieval para a história da filosofia. Transcendentais, neste contexto, são as noções mais comuns (comuníssimas) a que é possível reduzir os nossos conceitos das coisas, e que, para os filósofos medievais, eram pelo menos quatro: o ente, o uno, o verdadeiro e o bom. É através do pensamento acerca destas noções comuníssimas - transcendentais, porque transcendem a universalidade dos géneros máximos - que a filosofia medieval elabora a metafísica como ciência do ente enquanto ente, como teoria geral do ente, ou "ontologia" em sentido clássico. E qual é a relevância de $\mathrm{S}$. Tomás de Aquino na história da metafísica medieval, como "pensamento transcendental"? De acordo com Jan A. Aertsen, S. Tomás de Aquino oferece um primeiro modelo da filosofia dos transcendentais ${ }^{4}$, e o texto do artigo primeiro (a.1) da primeira questão (q.1) de Questões Disputadas sobre a Verdade é a fonte crucial desse modelo: "De veritate q.1, a.1, lidando com a questão 'O que é a verdade?', contém a derivação mais sistemática destas noções no século XIII e foi considerado 'o texto mais denso e formal em toda a história do

\footnotetext{
4 "Thomas Aquinas: A First Model" é o título do capítulo dedicado a S. Tomás de Aquino in Jan A. Aertsen, Medieval Philosophy as Transcendental Thought. From Philip the Chancellor (ca. 1225) to Francisco Suárez, Leiden/ Boston, Brill, 2012, pp. 209-271.
} 
pensamento ocidental"',5, por Cornelio Fabro ${ }^{6}$.

O artigo primeiro - "O que é a verdade?" - põe em questão a identidade ou diferença entre a verdade e o ente: a verdade identifica-se ou não com aquilo que é, o ente? Não faltava na tradição filosófica quem desse uma resposta afirmativa, e S. Tomás não o ignora, vindo até a dar interpretações integradoras dessas respostas afirmativas na sua própria posição, que é uma terceira via entre a afirmação absoluta da identidade entre a verdade e o ente e a negação absoluta dessa identidade. A posição de S. Tomás pode sintetizar-se assim: a verdade e o ente identificam-se na realidade, mas distinguem-se pela razão, ou conceptualmente, como hoje se costuma dizer. A verdade e o ente identificam-se na realidade, porque a verdade é, como os demais transcendentais convertíveis com o ente, um modo geral do ente; por isso se pode dizer que todo o ente é verdadeiro e todo o verdadeiro é um ente. Mas a verdade e o ente distinguem-se conceptualmente, porque a verdade é o modo geral do ente relativamente à alma cognitiva, e é esta relação, o conteúdo que a noção de verdade acrescenta à noção de ente. Esta posição de S. Tomás de Aquino, assim descrita em síntese, não se compreende, porém, sem aquela "derivação sistemática" dos transcendentais, como sublinha Jan A. Aertsen, e que se encontra na parte central da resposta deste artigo primeiro. Trata-se de uma análise dos transcendentais como modalidades do ente, que pode ser esquematizada como se segue:

1. Modos especiais do ente: as 10 categorias (Aristóteles), como, por exemplo, a substância, que é o ente por si (per se ens).

2. Modos gerais do ente:

2.2. Modos gerais do ente em si (ens in se), ou considerado absolutamente: 2.2.1. Modo geral do ente em si, que exprime algo afirmativamente no ente: coisa (res), ou o ente considerado em virtude da sua quididade ou essência.

2.2.2. Modo geral do ente em si, que exprime algo negativo no ente: uno (unum), ou ente considerado em virtude da sua indivisão.

\footnotetext{
5 “De veritate q.1, a.1, dealing with the question 'What is truth?', contains the most systematic derivation of these notions in the thirteenth century and has been called 'the most dense and formal text in the whole history of western thought'." Jan A. Aertsen, Op. cit., p. 211.

6 Cf. C. Fabro, "The Transcendentality of Ens-Esse and the Ground of Metaphysics", International Philosophical Quarterly 6 (1966), p. 407.
} 
2.3. Modos gerais do ente em ordem a outro (in ordine ad aliud), ou considerado em relação:

2.3.1. Modo geral do ente em ordem a outro, segundo a separação entre um e outro: algo (aliquid: quasi aliud quid).

2.3.2. Modos gerais do ente em ordem à alma, enquanto esta é potencialmente tudo, através do desejo e do conhecimento:

2.3.2.1. Modo geral do ente em ordem à alma desiderativa: bom (bonum).

2.3.2.2. Modo geral do ente em ordem à alma cognitiva: verdadeiro (verum).

Esta teoria dos modos do ente é o cerne da metafísica de $\mathrm{S}$. Tomás de Aquino, entendida como ciência do ente enquanto ente e das suas propriedades mais universais (transcendentais), e, portanto, como ontologia. De acordo com esta ontologia das modalidades do ente, qualquer ente é indissociável de uma essência, de uma unidade e de uma diferença, bem como de relações de adequação com o ente desiderativo e cognitivo que é a alma, relações que se exprimem pelos transcendentais da bondade e da verdade. À luz da metafísica tomasiana, a verdade tem, pois, um fundamento ontológico.

É, neste quadro ontológico, que tem aqui cabimento a definição de verdade, como adequação da coisa e do intelecto - veritas est adaequatio rei et intellectus - que S. Tomás de Aquino atribui a Isaac Israëli, letrado do círculo de Al-Kindi (séc. IX) e autor de um livro de definições, que era utilizado em versão latina (De definitionibus) pelos escolásticos do séc. XIII. Tal definição tornou-se um lugar tão comum em filosofia que costuma ser aplicada a qualquer época da história da filosofia. No entanto, convém não perder de vista o artigo de J. T. Muckle, "Isaac Israëli's definition of truth" (1933), no qual uma investigação que envolveu a consulta de três manuscritos do livro De definitionibus levou o autor a afirmar: "Em nenhum destes manuscritos encontrei a definição de verdade tão persistentemente atribuída a Isaac." ${ }^{77}$ Nas definições de verdade, enunciadas no livro de Isaac, falta, em especial, o termo adaequatio. Contudo, a formulação - veritas est adaequatio rei et intellectus - circulava já como definição de verdade em disputa entre os escolásticos da primeira metade do séc. XIII, como Filipe o Chanceler ${ }^{8}$. S. Tomás de Aquino não só adoptou essa definição como a justificou pela sua filosofia dos transcendentais, e esta é a novidade da sua posição. Mas era um tempo em que a novidade não ombreava em valor

\footnotetext{
7 "In none of these mss. did I find the definition of truth so persistently attributed to Isaac."

J. T. Muckle, "Isaac Israëli's definition of truth", Archives d'Histoire Doctrinale et Littéraire du Moyen Âge, 8e année (1933), p. 7.

8 Cf. Jan A. Aertsen, Op. cit., p. 118.
} 
com a autoridade, antes podia causar suspeita e, por isso, a definição devia aparecer revestida de autoridade. Robustecida pela autoridade de Isaac, vingou a definição da verdade, como adequação entre a coisa e o intelecto, com a qual culmina a resposta de $\mathrm{S}$. Tomás de Aquino à pergunta "O que é a verdade?", no texto a seguir traduzido.

A tradução é tanto quanto possível próxima da letra, respeitando o vocabulário técnico do latim escolástico de S. Tomás de Aquino. Sempre que a versão portuguesa faça perder a força da expressão latina original, esta é oportunamente indicada entre parênteses curvos no texto da tradução. Os lugares de obras citadas por S. Tomás de Aquino são também oportunamente indicados entre parênteses rectos no texto da tradução, de acordo com a informação dada no aparato crítico da edição utilizada para a tradução. A edição do texto traduzido é a edição leonina: Opera Omnia Iussu Leonis XIII P. M. Edita. Tomus XXII: Quaestiones Disputatae de Veritate, Cura et Studio Fratrum Praedicatorum, Volumen I, Fasc. 2, Romae ad Sanctae Sabinae, 1970 (pp. 3-8). 


\title{
SÃO TOMÁS DE AQUINO \\ QUESTÕES DISPUTADAS SOBRE A VERDADE
}

\section{Questão 1}

Da verdade

\author{
Artigo 1 \\ O que é a verdade?
}

A questão é acerca da verdade. E primeiro pergunta-se: o que é a verdade? Parece que o verdadeiro é totalmente o mesmo que o ente: Agostinho diz, no livro dos Solilóquios [II, 5], que "o verdadeiro é aquilo que é"; portanto, o verdadeiro significa totalmente o mesmo que o ente.

2. Respondendo dizia que são o mesmo segundo os supostos (supposita), mas diferem quanto à noção (ratio). - Contra: a noção (ratio) de qualquer coisa é aquilo que é significado pela sua definição; mas aquilo que é (id quod est), é tomado por Agostinho como definição do verdadeiro, depois de excluídas algumas outras definições; portanto, como o verdadeiro e o ente convêm segundo aquilo que é, parece que são o mesmo quanto à noção.

3. Além disso, todas as coisas que diferem quanto à noção comportam-se de modo que uma delas pode ser entendida sem a outra. Daí que Boécio diga, no livro Das hebdómadas, que Deus pode ser entendido existir, se por pouco tempo for separada pelo intelecto a sua bondade; o ente, porém, de modo nenhum pode ser entendido, se o verdadeiro for separado, porque é entendido por isto que é verdadeiro; portanto, o verdadeiro e o ente não diferem quanto à noção.

4. Além disso, se o verdadeiro não é o mesmo que o ente, é necessário que seja uma disposição do ente; mas não pode ser uma disposição do ente: de facto, não é uma disposição totalmente corruptora, pois, se assim fosse, seguir-se-ia 'é verdadeiro, logo não é um ente', tal como se segue 'é um homem morto, logo não é um homem'; de modo similar, não é uma disposição restritiva, pois, se assim fosse, não se seguiria 'é verdadeiro, logo é', tal como não se segue 'tem dentes brancos, logo é branco'; de modo similar, não é uma disposição contractiva ou especificadora, porque assim não se converteria com o ente. Portanto, o verdadeiro e o ente são totalmente o mesmo. 
5. Além disso, as coisas que têm uma única disposição são o mesmo; mas o verdadeiro e o ente têm a mesma disposição; logo, são o mesmo. Diz-se, de facto, em Metafísica II [993 b 30]: "A disposição de uma coisa no ser é como a sua disposição na verdade"; portanto, o verdadeiro e o ente são totalmente o mesmo.

6. Além disso, todas as coisas que não são o mesmo diferem de algum modo; mas o verdadeiro e o ente de modo nenhum diferem, porque não diferem por essência, uma vez que todo o ente é verdadeiro pela sua essência, nem diferem por algumas diferenças, porque seria necessário que conviessem em algum género comum; portanto, são totalmente o mesmo.

7. Igualmente, se não são totalmente o mesmo, é necessário que o verdadeiro adicione algo além do ente; mas o verdadeiro nada adiciona além do ente, como se fosse também mais do que o ente. O que é evidente pelo Filósofo, em Metafisica IV [1011 b 25], onde diz aquilo que nós dizemos quando definimos o verdadeiro, 'que dizemos ser aquilo que é ou não ser aquilo que não é', e assim o verdadeiro inclui o ente e o não ente; portanto, o verdadeiro não adiciona algo além do ente, e assim parece que o verdadeiro é totalmente o mesmo que o ente.

MAS CONTRA: 'a nugação é a repetição da mesma coisa inútil' [Arist., Tóp. V, 2 (130 a 34); Ref. Sof. 3 (165 b 15)]; se, portanto, o verdadeiro fosse o mesmo que o ente, haveria uma nugação quando se diz o ente verdadeiro, o que é falso; portanto, não são o mesmo.

2. Igualmente, o ente e o bom convertem-se entre si; mas o verdadeiro não se converte com o bom: de facto, algo é verdadeiro, que não é bom, como alguém prostituir-se; portanto, nem o verdadeiro se converte com o ente, e assim não são o mesmo.

3. Além disso, segundo Boécio, no livro Das hebdómadas, em todas as criaturas, "diverso é o ser e aquilo que é"; mas o verdadeiro significa o ser da coisa; logo, o verdadeiro é diverso daquilo que é nas coisas criadas. Mas aquilo que é, é o mesmo que o ente; portanto, o verdadeiro nas criaturas é diverso do ente.

4. Além disso, é necessário que todas as coisas, que se relacionam entre si como anterior e posterior, sejam diversas. Mas o verdadeiro e o ente relacionam-se entre si deste modo, como se diz no livro Das causas [4], 
"a primeira das coisas criadas é o ser", e o Comentador, sobre o mesmo livro, diz que todas as outras coisas se dizem por determinação formal (per informationem) do ente, e, assim, são posteriores ao ente. Portanto, o verdadeiro e o ente são diversos.

5. Além disso, as [noções] que se dizem em comum da causa e dos causados, possuem mais unidade na causa do que nos causados, e, principalmente em Deus do que nas criaturas. Mas, em Deus, estas quatro [noções] - o ente, o uno, o verdadeiro e o bom - são apropriadas de modo que o ente pertença à essência, o uno à pessoa do Pai, o verdadeiro à pessoa do Filho, e o bom à pessoa do Espírito Santo. As pessoas divinas, porém, distinguem-se não só pela razão mas também realmente, e, por isso, não se predicam umas das outras. Portanto, com muito mais forte razão nas criaturas, as quatro noções referidas devem diferir mais do que racionalmente.

RESPOSTA. Deve dizer-se que tal como nos demonstráveis é necessário fazer-se uma redução a alguns princípios por si evidentes para o intelecto, assim também ao investigar aquilo que é cada coisa; de contrário, nos dois casos, regredir-se-ia ao infinito, e, assim, pereceria totalmente a ciência e o conhecimento das coisas. Aquilo, porém, que o intelecto concebe primeiro, como evidentíssimo, e no qual resolve todas as concepções, é o ente, como diz Avicena no princípio da sua Metafísica [I, 6]; por isso, é necessário que todas as outras concepções do intelecto sejam tomadas por adição ao ente. Mas ao ente não podem ser adicionadas coisas como que estranhas, do modo como a diferença é adicionada ao género ou o acidente ao sujeito, porque qualquer natureza é essencialmente um ente; por isso, prova também o Filósofo, em Metafísica III [998 b 22], que o ente não pode ser um género. Não obstante, diz-se que algumas [noções] adicionam [algo] além do ente enquanto exprimem um modo do próprio ente, que o nome de ente não exprime, o que acontece de duas maneiras. Uma, de forma que o modo expresso seja um modo especial do ente. Há, de facto, diversos graus de entidade segundo os quais se consideram diversos modos de ser, e, de acordo com estes modos, consideram-se os diversos géneros das coisas: a substância, de facto, não adiciona além do ente alguma diferença que designe alguma natureza adicionada ao ente, mas pelo nome de substância exprime-se um modo especial de ser, a saber, o ente por si (per se ens), e assim acontece nos outros géneros.

A outra, de forma que o modo expresso seja um modo geral consequente de todo ente, e este modo pode ser considerado duplamente: de um modo, 
segundo o que se segue de cada ente em si; de outro modo, segundo o que se segue de um ente em ordem a outro. Se, do primeiro modo, este subdivide-se em dois, porque ou se exprime no ente algo afirmativamente ou negativamente. Não se encontra, porém, algo afirmativamente dito de modo absoluto, que possa ser considerado em todo o ente, a não ser a sua essência segundo a qual se diz ser, e assim impõe-se este nome coisa (res), que difere do ente, segundo Avicena, no princípio da Metafisica [I, 6], porque o ente é assumido a partir do acto de ser, mas o nome de coisa exprime a quididade ou a essência do ente. Por sua vez, a negação consequente de todo o ente absolutamente considerado é a indivisão, e esta é o que exprime este nome uno: de facto, nada é uno, a não ser o ente indiviso. Se, porém, o modo do ente for considerado do segundo modo, isto é, segundo a ordem de um para outro, isso pode dar-se duplamente. De um modo, segundo a divisão de um relativamente a outro, e isto é o que exprime este nome algo: diz-se, de facto, algo (aliquid) como sendo outro quê (aliud quid). Por isso, tal como o ente se diz uno enquanto é indiviso em si, assim também se diz algo enquanto é dividido dos outros. Do outro modo, segundo a conveniência de um ente com outro, e isto decerto não pode dar-se a não ser que se considere algo que possa naturalmente convir com todo o ente. Tal é o caso da alma, que "de algum modo é tudo", como se diz em Da alma III [431 b 21]. Na alma, porém, há uma capacidade cognitiva e outra apetitiva: a conveniência do ente com o desejo é o que exprime este nome bom, e por isso se diz, no princípio da Ética, que "bom é aquilo que todos desejam" [I, 1094 a 3]; a conveniência do ente com o intelecto é o que exprime este nome verdadeiro.

Todo o conhecimento se perfaz por assimilação do cognoscente à coisa conhecida, de modo que a dita assimilação é a causa do conhecimento, assim como a vista, por se dispor segundo a espécie da cor, conhece a cor. Portanto, a primeira preparação do ente para o intelecto é a fim de que o ente concorde com o intelecto, concordância essa que se diz adequação do intelecto e da coisa, e nisto se perfaz formalmente a noção de verdadeiro. Isto é, portanto, aquilo que o verdadeiro adiciona além do ente, ou seja, a conformidade ou a adequação da coisa e do intelecto, conformidade à qual, como foi dito, se segue o conhecimento da coisa: assim a entidade da coisa precede a noção de verdade, mas o conhecimento é um efeito da verdade. Consequentemente, descobrem-se três maneiras de definir a verdade ou o verdadeiro. Uma maneira, segundo aquilo que precede a noção de verdade e no qual se funda o verdadeiro: e assim define Agostinho, no livro dos Solilóquios, "o verdadeiro é aquilo que é" [II, 5]; e Avicena, na sua Metafísica, "a verdade de cada coisa é a propriedade do seu ser que 
lhe foi firmado" [VIII, 6]; e alguns assim "o verdadeiro é a indivisão do ser e daquilo que é". Outra maneira de definir é segundo aquilo no qual a noção de verdadeiro se perfaz formalmente: e assim diz Isaac que "a verdade é a adequação da coisa e do intelecto"; e Anselmo, no livro $D a$ Verdade [11], "a verdade é a rectitude perceptível só pela mente" - de facto, esta rectitude diz-se segundo alguma adequação -; e o Filósofo diz, em Metafísica IV [1011 b 25], aquilo que nós dizemos quando definimos o verdadeiro, 'quando se diz ser aquilo que é ou não ser aquilo que não é'. De uma terceira maneira, o verdadeiro é definido segundo o efeito consequente: e assim diz Hilário [Da Trindade V, 3] que "o verdadeiro é o ser declarativo e manifestativo"; e Agostinho, no livro Da Verdadeira Religião, "a verdade é aquela pela qual se mostra aquilo que é" [36], e, no mesmo livro, "a verdade é aquela segundo a qual julgamos acerca das coisas inferiores" [31].

1. Quanto ao primeiro [argumento], deve dizer-se, portanto, que aquela definição de Agostinho é dada na medida em que a verdade tem fundamento na realidade, e não na medida em que a noção de verdadeiro se completa na adequação da coisa ao intelecto. - Ou deve dizer-se que, quando se diz que o verdadeiro é aquilo que é, aquele 'é' não é aí tomado enquanto significa o acto de ser (actum essendi), mas enquanto é uma marca do intelecto que compõe, uma vez que significa a afirmação de uma proposição, de modo que o sentido seja: o verdadeiro é aquilo que é, isto é, quando se diz que é, acerca de algo que é. Por conseguinte, assim revertem ao mesmo, a definição de Agostinho e a definição do Filósofo, acima referida.

2. Quanto ao segundo, é evidente a solução pelo que foi dito.

3. Quanto ao terceiro, deve dizer-se que podem ser considerados dois modos de algo ser entendido sem outro [algo]. De um modo, porque algo é entendido sem que outro seja entendido, e assim as coisas que diferem quanto à noção (ratio) comportam-se de forma que uma pode ser entendida sem a outra. De outro modo pode considerar-se que algo é entendido sem outro, porque é entendido sem que o outro exista, e assim o ente não pode ser entendido sem o verdadeiro, porque o ente não pode ser entendido sem isto que concorda ou se adequa ao intelecto. Mas não é necessário que quem quer que entenda a noção de ente entenda a noção de verdadeiro, assim como não é necessário que quem quer que entenda o ente, entenda o intelecto agente, e, no entanto, nada pode ser entendido sem o intelecto agente. 
4. Quanto ao quarto, deve dizer-se que o verdadeiro é uma disposição do ente, não como se adicionasse alguma natureza, nem como se exprimisse algum modo especial do ente, mas como algo que geralmente se encontra em todo o ente, embora não se exprima pelo nome de ente. Por isso, não é necessário que seja uma disposição ou corruptora ou restritiva ou, em parte, contractiva.

5. Quanto ao quinto, deve dizer-se que não se toma aí disposição segundo aquilo que está no género da qualidade, mas segundo aquilo que implica alguma ordem: de facto, como aquelas coisas, que são causa do ser de outras, são maximamente entes, e aquelas que são causa da verdade, são maximamente verdadeiras, conclui o Filósofo que é a mesma, a ordem de alguma coisa no ser e na verdade, de modo que onde se encontra aquilo que é maximamente ente, isso é maximamente verdadeiro. Daí que isto não se explique porque o ente e o verdadeiro sejam o mesmo quanto à noção, mas porque algo, na medida em que possui entidade, pode adequar-se ao intelecto, e, assim, a noção de verdadeiro segue-se à noção de ente.

6. Quanto ao sexto, deve dizer-se que o verdadeiro e o ente diferem quanto à noção, porque algo pertence à noção de verdadeiro, que não pertence à noção de ente; não, porém, de modo que algo pertença à noção de ente, que não pertença à noção de verdadeiro. Por isso, nem diferem por essência, nem se distinguem por diferenças opostas entre si.

7. Quanto ao sétimo, deve dizer-se que o verdadeiro não é mais do que o ente: de facto, o ente tomado de algum modo diz-se do não ente, na medida em que o não ente é apreendido pelo intelecto. Por isso, em Metafisica IV [1003 b 5], diz o Filósofo que a negação ou a privação do ente diz-se de certo modo ente. Por isso, também Avicena diz, no princípio da sua Metafísica [I, 6], que não se pode formar uma enunciação senão acerca do ente, porque é necessário que aquilo de que se forma a proposição seja apreendido pelo intelecto. Por conseguinte, é evidente que todo o verdadeiro é de algum modo um ente. 
1. Quanto ao primeiro [argumento] dos que são apresentados contra, deve dizer-se que não há nugação, quando se diz 'ente verdadeiro', porque algo se exprime pelo nome de verdadeiro, que não se exprime pelo nome de ente, não porque difiram realmente.

2. Quanto ao segundo, deve dizer-se que, embora alguém prostituir-se seja um mal, na medida em que algo possui entidade, comporta a possibilidade de conformar-se ao intelecto, e, consequentemente, obtém-se aí a noção de verdadeiro, e assim é evidente que nem o verdadeiro excede nem é excedido pelo ente.

3. Quanto ao terceiro, deve dizer-se que, quando se diz 'diverso é o ser e aquilo que é', distingue-se o acto de ser daquilo ao qual esse acto convém; mas o nome de ente é assumido a partir do acto de ser, não a partir daquilo ao qual convém o ser, e, por isso, o argumento não procede.

4. Quanto ao quarto, deve dizer-se que o verdadeiro é posterior ao ente na medida em que a noção de verdadeiro difere da noção de ente, do modo referido.

5. Quanto ao quinto, deve dizer-se que aquele argumento é deficiente em três aspectos. Primeiro, porque, embora as três pessoas divinas se distingam na realidade, as noções apropriadas às pessoas não diferem na realidade mas apenas pela razão. Em segundo lugar, porque, embora as pessoas realmente se distingam entre si, não se distinguem realmente da essência; daí que nem o verdadeiro, que se apropria à pessoa do Filho, [se distingue] do ente, que se mantém por parte da essência. Em terceiro lugar, porque, embora o ente, o uno, o verdadeiro e o bom possuam maior unidade em Deus do que nas coisas criadas, não é necessário que por se distinguirem em Deus também se distingam nas coisas criadas realmente. Isto acontece de facto com aquelas coisas que não possuem, pela sua noção, condição de unidade real, como a sabedoria e o poder, que, embora possuam unidade real em Deus, distinguem-se realmente nas criaturas. Mas o ente, o uno, o verdadeiro e o bom, segundo a sua noção, possuem condição de unidade real; daí que, onde quer que se encontrem, realmente são um, embora seja mais perfeita a unidade daquela realidade segundo a qual estão unidos em Deus do que a daquela realidade segundo a qual estão unidos nas criaturas. 